\title{
Penerapan Model ARIMA dalam Memprediksi Jumlah Tindak Kriminalitas di Wilayah POLRESTA Manado Provinsi Sulawesi Utara
}

\author{
Karmelin Mendome ${ }^{a^{*}}$, Dr. Nelson Nainggolan, M.Si ${ }^{a}$, Prof. Dr.Ir. John \\ Kelkenusa,M.S ${ }^{\mathbf{a}}$
}

a*Jurusan Matematika, FMIPA, Unsrat, Manado

\begin{tabular}{l} 
K A T A K U N C I \\
\hline Model Arima \\
Tindak Kriminalitas
\end{tabular}

\begin{abstract}
A B S T R A K
Tujuan penelitian ini adalah menentukan model Autoregressive Integrated Moving Average (ARIMA) untuk memprediksi jumlah kejadian tindak kriminalitas di Wilayah Kepolisian Resort Kota (POLRESTA) Manado. Data yang digunakan adalah data bulanan jumlah kejadian tindak kriminalitas dari bulan Januari 2010 sampai Mei 2016. Hasil penelitian menunjukan Model ARIMA $(1,1,0)$ cukup baik untuk memprediksi jumlah kejadian tindak kriminalitas di Wilayah POLRESTA Manado dengan presentase rata-rata dari nilai selisih antara nilai aktual dan nilai prediksi sebesar $13,81 \%$. Untuk prediksi jumlah kejadian tindak kriminalitas pada bulan Juni, Juli dan Agustus tahun 2016 menunjukkan pola yang menurun.
\end{abstract}

KE Y W O R D S

ARIMA models

Crime Act

\begin{abstract}
A B S T R A C T
The purpose of this study was determining the model Autoregressive Integrated Moving Average (ARIMA) to predict the number of occurrences of crime in the Territory Police Resort City Manado. The data used are the monthly data of the number of occurrences of crime from January 2010 to May 2016. The results showed that the ARIMA $(1,1,0)$ well enough to predict the number of occurrences of crime in the Territory POLRESTA Manado with a percentage of the average of the value of the difference between the actual value and the predictive value of $13.81 \%$. The prediction of the number of incidents of crime in June, July and August 2016 showed a declining pattern.
\end{abstract}

\section{Pendahuluan}

Tindak kriminalitas dapat diartikan sebagai perbuatan pelaku kriminal atau kejahatan. Tindak kriminal atau Tindak kejahatan merupakan suatu masalah sosial yang tidak dapat dihindari oleh kehidupan bermasyarakat. Tindak kriminal pun menjadi suatu ancaman bagi masyarakat luas. Dari tahun ke tahun, tingkat kriminalitas terkadang mengalami penurunan atau peningkatan. Kriminalitas di Indonesia mempunyai tingkatan yang berbeda-beda di setiap daerahnya dan setiap tahunnya, khususnya Kota Manado yang merupakan Ibu Kota Provinsi Sulawesi Utara. Oleh karena itu, diperlukan informasi untuk mengetahui jumlah kejadian tindak kriminalitas di Wilayah Kota Manado agar dapat diakses oleh masyarakat atau dengan distribusi informasi ke publik dan dapat mempermudah aparat kepolisian untuk mengambil keputusan untuk mengetahui jumlah kejadian tindak kriminalitas di kota Manado.

Penelitian ini bertujuan Menentukan model Autoregressive Integrated Moving Average (ARIMA) untuk memprediksi jumlah kejadian tindak kriminalitas di Wilayah Kepolisian Resort Kota (POLRESTA) Manado serta menjadi bahan pertimbangan pemikiran khususnya bagi Aparat 
Kepolisian di Wilayah Kepolisian Resort Kota (POLRESTA) Manado Provinsi Sulawesi Utara dalam membuat strategi untuk mengurangi kejadian tindak kriminalitas di Kota Manado.

2. Material dan Metode

\subsection{Pengertian tindak kriminalitas}

Kriminal berasal dari kata "crimen" yang berarti kejahatan. Kriminalitas merupakan segala macam bentuk tindakan dan perbuatan yang merugikan secara ekonomis dan psikologis yang melanggar hukum yang berlaku dalam negara Indonesia serta norma-norma sosial dan agama.

Dalam Proses hukum pidana, terdapat prosedur atau hukum acara yang saat ini diatur dalam UU Nomor 8 Tahun 1981 tentang Kitap Undang-Undang Hukum Acara Pidana (KUHAP). Untuk lebih memahaminya, upaya hukum untuk kasus pidana umum adalah sebagai berikut (a) Laporan, (b) Penyelidikan, (c) Penyidik, (d) Penangkapan, (e) Penahanan, (f) Penggeledahan, (g) Penyitaan, (h) Bantuan hukum, (i) Prapenuntutan dan penuntutan, (j) Praperadilan, (k) Sidang pengadilan (Visimedia, 2016).

\subsection{Prediksi}

Predikasi adalah suatu proses memperkirakan secara sistematis tentang sesuatu yang paling mungkin terjadi di masa depan berdasarkan informasi masa lalu dan sekarang yang dimiliki, agar kesalahannya dapat diperkecil. Prediksi tidak harus memberikan jawaban secara pasti suatu kejadian yang akan terjadi, melainkan berusaha untuk mencari jawaban sedekat mungkin yang akan terjadi (Lilipaly, 2014).

\subsection{Model Time Series (Deret Waktu)}

Analisis deret waktu dikenalakan oleh George E. P. Box dan Gwilym M. Jenkins pada tahun 1970 melalui bukunya Time Series Analysis : forecasting and control. Sejak saat itu, time series mulai banyak dikembangkan. Dasar pemikiran time series adalah pengamatan sekarang $\left(Z_{t}\right)$ tergantung pada satu atau beberapa pengamatan sebelumnya $\left(\mathrm{Z}_{\mathrm{t}-1}\right)$ (Iriawan N dan Astuti P, 2006).

Suatu data pengamatan dikatakan stasioner jika data tersebut mempunyai nilai mean dan variansi yang relatif konstan dari waktu ke waktu (Widarjono, 2007). Sebaliknya, data pengamatan yang tidak stasioner mempunyai mean dan variansi yang tidak konstan atau berubah seiring dengan berubahnya waktu.

Autokorelasi adalah korelasi antara suatu variabel satu atau lebih periode sebelumnya dengan dirinya sendiri. Rumus fungsi autokorelasi menurut Mulyana (2004) adalah sebagai berikut:

$$
\rho_{k}=\frac{\sum_{t=1}^{n-k}(X-\bar{X})\left(X_{t+k}-\bar{X}\right)}{\sum_{t=1}^{n}\left(X_{t}-\bar{X}\right)^{2}}
$$

dimana :

$\rho_{k}$ : koefisien korelasi pada lag-k

$\bar{X}$ : rata-rata observasi.

Autokorelasi Parsial disingkat PACF digunakan untuk mengukur tingkat keeratan (association) antara $X_{t}$ dan $X_{t-k}$, apalagi pengaruh dari lag 1,2 , $3, \ldots$, dan seterusnya sampai k-1 diangkap terpisah. Menurut Wei (1990), rumus fungsi autokorelasi parsial ditulis dengan:

$$
\phi_{k+1, k+1}=\frac{\rho_{k+1}-\sum_{j=1}^{k-1} \phi_{k j} \rho_{k+1-j}}{1-\sum_{j=1}^{k-1} \phi_{k j} \rho_{j}}
$$

dimana, $\rho_{k}=$ nilai autokorelasi lag $-k$

\subsection{Identifikasi Model Melalui Plot ACF dan PACF}

Proses pemilihan model yang tepat dilakukan dengan mengidentifikasikan orde AR dan MA pada grafik ACF dan PACF (Arsyad, 1995).

a) Jika autokorelasi secara eksponensial melemah menuju nol berarti terjadi proses $\operatorname{AR}(p)$.

b) Jika autokorelasi parsial melemah secara eksponensial menuju nol berarti terjadi proses $\operatorname{MA}(q)$.

c) Jika keduanya melemah menjadi nol maka model tersebut adalah gabungan dari AR dan MA yaitu $\operatorname{ARMA}(p, q)$.

\subsection{Model Autoregressive Moving Average (ARMA)}

Model autoregresif adalah model yang menyatakan bahwa data pada periode sekarang dipengaruhi oleh data pada periode sebelumya. Model Autoregresif dengan ordo $p$ disingkat dengan AR $(p)$.

Model Moving Average menyatakan hubungan antara nilai pengamatan dari kesalahan peramalan sekarang dan masa lalu yang berurutan, persamaan itu dianamakan moving average model. Model moving average dengan orde $q$ disingkat $\mathrm{MA}(q)$.

Model Autoregressive Moving Average (ARMA) ialah gabungan dari model $\operatorname{AR}(p)$ dan $\operatorname{MA}(q)$ sehingga memiliki asumsi bahwa data periode sekarang dipengaruhi oleh data periode lampaunya dan nilai lampau kesalahannya. Model ARMA dengan orde $p$ dan $q$ ditulis $\operatorname{ARMA}(p, q)$ atau ARMA $(p, 0, q)$. Menurut Mulyono (2000), bentuk umum dari model ini adalah sebagai berikut:

$$
\begin{aligned}
Z_{t}= & \mu+\phi_{1} Z_{t-1}+\phi_{2} Z_{t-2}+\ldots+\phi_{p} Z_{t-p}+e_{t} \\
& -\theta_{1} e_{t-1}-\theta_{2} e_{t-2}-\ldots-\theta_{q} e_{t-q}
\end{aligned}
$$

dimana :

$$
\begin{array}{ll}
Z_{t} & : \text { Variabel time series } \\
\mu & : \text { Konstanta } \\
\theta_{1}, \theta_{2}, \ldots, \theta_{q} & : \text { Koefisien parameter moving } \\
& \text { average ke- } q \\
\phi_{1}, \phi_{2}, \ldots, \phi_{p} & : \text { Koefisien parameter } \\
& \text { autoregressive ke- } p \\
e_{t-q} & : \text { Sisaan pada saat ke-t- } q .
\end{array}
$$

Salah satu cara yang umum dipakai adalah metode pembedaan (differencing). Proses selisih dilakukan jika data stasioner dalam rata-ratanya. Metode ini dilakukan dengan cara mengurangi nilai data pada suatu periode dengan nilai data periode sebelumnya yang dapat dirumuskan sebagai berikut (Salmon, 2015):

$$
W_{t}=Z_{t}-Z_{t-1}
$$


2.6 Model Autoregrssive Integrated Moving Average (ARIMA)

Proses ARIMA digunakan apabila proses time series tidak stasioner. Secara umum persamaan model ARIMA adalah

$$
\begin{aligned}
W_{t}= & \mu+\phi_{1} W_{t-1}+\phi_{2} W_{t-2}+\ldots+\phi_{p} W_{t-p} \\
& +e_{t}-e_{t}-\theta_{1} e_{t-1}-\ldots-\theta_{q} e_{t-q} \\
\text { dimana } & W_{t}=Z_{t}-Z_{t-1} .
\end{aligned}
$$

\subsection{Penaksiran Parameter}

Menurut iriawan dan Astuti (2006), Mean Squared Error (MSE) atau rata-rata kuadrat terkecil merupakan suatu kriteria dalam memilih model terbaik. Semakin kecil nilai MSE yang dihasilkan suatu model maka semakin baik. Dapat dengan menggunakan persamaan :

$$
\begin{array}{r}
M S E=\frac{1}{n} \sum_{t=1}^{n} e_{t}^{2}= \\
t=1 n Z t-Z t 2 n \ldots \ldots \ldots \ldots \ldots \ldots . . .
\end{array}
$$

dimana :

$n=$ banyaknya data

$Z_{t}=$ data aktual pada waktu $\mathrm{t}$

$\hat{Z}_{t}=$ data hasil prediksi pada waktu $\mathrm{t}$

\subsection{Uji Diagnostik}

Uji diagnostik perlu dilakukan untuk menguji bahwa model tersebut cukup memadai dan menentukan model mana yang terbaik untuk peramalan (Makridakis, 1999). Model dikatakan memadai jika asumsi dari error memenuhi proses white noise dan berdistribusi normal. Apabila dijumpai penyimpangan yang cukup serius maka harus dirumuskan kembali model yang baru, selanjutnya diestimasi dan dilakukan pemeriksaan kembali.

\section{Hasil dan Pembahasan}

\subsection{Data Jumlah Kejadian Tindak Kriminalitas}

Data jumlah kejadian tindak kriminalitas merupakan data sekunder diambil dari kantor Polresta Manado. Data tersebut merupakan data pada tingkat yang dilaporkan oleh masyarakat ke kantor polisi di wilayah hukum kota Manado.

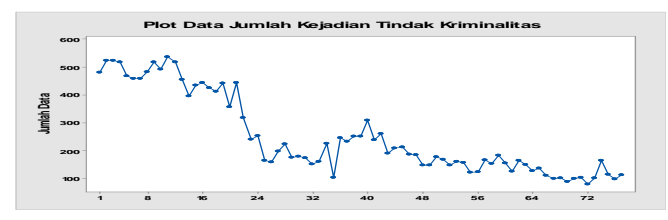

Gambar 1. Plot Data jumlah kejadian tindak kriminalitas periode bulan Januari 2010 sampai dengan bulan Mei 2016.

Dari Gambar 1 terlihat bahwa data menunjukan pola trend menurun. Oleh karena itu, dapat dikatakan data belum stasioner.

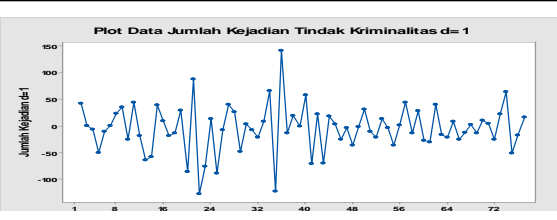

Gambar 2. Plot Data Jumlah Kejadian Tindak Kriminalitas dengan Selisih Orde 1.

Dalam hal ini, ketidakstasioneran dapat dihilangkan dengan proses selisih ( differencing). Gambar 2 menunjukan bahwa data telah stasioner setelah dilakukan proses selisih satu kali.

\section{a. Identifikasi model dan Penentuan Parameter}

Identifikasi model dilakukan dengan memperhatikan perilaku perilaku Fungsi ACF dan PACF. Perilaku ACF menunjukkan bahwa setelah lag 1 secara pelahan mengecil mendekati nol sedangkan pada PACF mendekati nol setelah lag pertama. Kedua hal ini mengidentifikasikan bahwa data tersebut tidak bersifat stasioner sedangkan analisis ARIMA dibutuhkan data yang bersifat stasioner.

Dengan menggunakan soffware Stasistika hasil identifikasi menghasilkan kemungkinan model yang dipilih dituangkan pada Tabel 1.

Tabel 1. Nilai mean square Error (MSE) dari Data Jumlah Kejadian Tindak Kriminalitas.

\begin{tabular}{|c|c|}
\hline Model & $\begin{array}{c}\text { Mean Squared } \\
\text { Error (MSE) }\end{array}$ \\
\hline ARIMA $(0,1,1)$ & 1682 \\
\hline ARIMA $(1,1,1)$ & 1662 \\
\hline ARIMA $(1,1,0)$ & 1642 \\
\hline
\end{tabular}

Maka Model yang akan dipilih dalam penelitian ini adalah model ARIMA $(1,1,0)$ dengan nilai MSE 1642.

b. Menentukan Persamaan ARIMA $(\mathbf{1 , 1}, \mathbf{0})$ pada Data Jumlah Kejadian Tindak Kriminalitas.

Hasil penaksiran parameter model ARIMA $(1,1,0)$ diperoleh koefisien AR 1= -0,4001, dan konstanta $=-8,088$. Dibuat persamaan untuk model ARIMA $(1,1,0)$ menjadi :

$$
\begin{aligned}
& Z_{t}-Z_{t-1}=\mu+\emptyset_{1}\left(Z_{t-1}-Z_{t-2}\right) \\
& Z_{t}=\mu+\left(1+\emptyset_{1}\right) Z_{t-1}-\emptyset_{1} Z_{t-2} \\
& Z_{t}=-8,088+(1-0,4001) Z_{t-1}+0,4001 \\
& Z_{t}=-8,088+0,5999 Z_{t-1}+0,4001 Z_{t-2}
\end{aligned}
$$

\section{c. Diagnostik Model ARIMA $(1,1,0)$ data Jumlah Kejadian Tindak Kriminalitas.}

Diagnostik dilakukan dengan melihat perilaku dari residual model $\operatorname{ARIMA}(1,1,0)$. Histogram dan normal probability dari residual dapat dilihat pada Gambar 3 dan Gambar 4. 


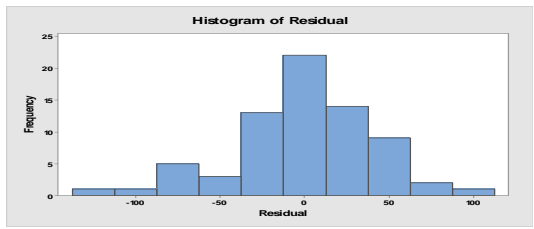

Gambar 3. Histogram dari Residual Model $\operatorname{ARIMA}(1,1,0)$

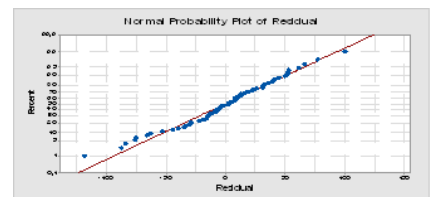

Gambar 4. Normal Probability Plot dari residual Model ARIMA $(1,1,0)$

Pada Gambar 3 terlihat grafik Histogram of Residual membentuk diagram normal hal ini menandakan bahwa residual sudah memenuhi asumsi berdistribusi normal. Selanjutnya, pada Gambar 4 terlihat bahwa residual mengikuti garis lurus yang mengartikan bahwa residual berdistribusi normal. Oleh karena itu, dalam hal ini residual menunjukkan bahwa Asumsi White Noise sudah terpenuhi.

Selanjutnya, model yang sudah dipilih dapat digunakan untuk prediksi. Pada Gambar 5 terlihat bahwa jumlah kejadian tindak kriminalitas periode bulan Februari 2010 sampai bulan Mei 2016 tidak terlalu berbedah jauh dengan hasil prediksi

Gambar 5. Data Jumlah Kejadian Tindak

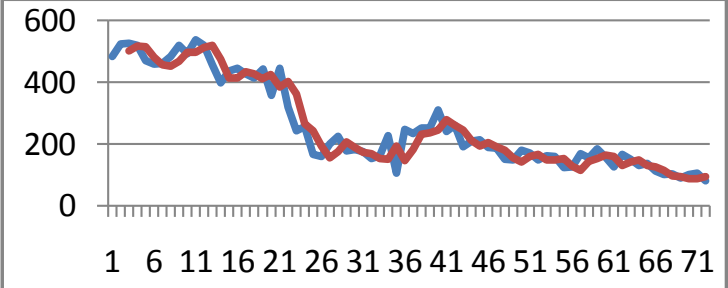

Kriminalitas Sebenarnya dan Prediksinya Bulan Februari 2010 sampai Mei 2016

\section{e. Prediksi data Jumlah Kejadian Tindak Kriminalitas Periode 3 bulan}

Model ARIMA(1,1,0) yang diperoleh sudah memenuhi asumsi dimana residualnya merupakan white noise. Oleh karena itu, model dapat diaplikasikan untuk memprediksi kejadian waktu berikutnya. Pada Tabel 2 diberikan prediksi 3 bulan berikutnya.

Tabel 2. Jumlah Kejadian Tindak Kriminalitas di Wilayah POLRESTA Manado Periode Bulan Juni Agustus 2016.

\begin{tabular}{|l|l|c|}
\hline \multicolumn{1}{|c|}{ Periode } & Prediksi & Aktual \\
\hline Juni 2016 & 99 & - \\
\hline Juli 2016 & 92 & - \\
\hline Agustus 2016 & 87 & - \\
\hline
\end{tabular}

\section{Kesimpulan}

1. Model time series untuk prediksi jumlah kejadian tindak kriminalitas di Wilayah POLRESTA Manado, menggunakan data periode Januari 2010 sampai Desember 2015 adalah ARIMA $(1,1,0)$ yaitu dengan persamaan:

$Z_{t}=-8,088+0,5999 Z_{t-1}+$ $0,4001 Z_{t-2}$.

2. Model ARIMA $(1,1,0)$ cukup baik untuk memprediksi jumlah kriminalitas di wilayah POLRESTA Manado dilihat dari pengujian diagnostik dan presentase rata-rata dari nilai selisih antara nilai aktual dan nilai prediksi sebesar 13,81\%.

3. Untuk prediksi jumlah kejadian tindak kriminalitas dikota Manado pada bulan Juni Agustus tahun 2016 menunjukkan pola menurun, yaitu berturut-turut 99, 92, dan 87 kejadian.

\section{Daftar Pustaka}

Arsyad, Lincolin. 1995. Peramalan Bisnis. Ghalia Indonesia, Jakarta.

Irawan, N dan Astuti, P. S. 2006. Mengolah Data Statistik dengan Mudah Menggunakan Minitab 14. Penerbit Andi, Yogyakarta.

Lilipaly, G. S. 2014. Prediksi Harga Saham PT. BRI, Tbk. Menggunakan Metode ARIMA (Autoregressive Integrated Moving Average) [skripsi]. FMIPA UNSRAT, Manado

Makridakis, S., Wheelwright, S.C., \& McGee, V.E. 1999. Metode dan Aplikasi PeramalanJilid 1 Edisi Kedua. Terjemahan Ir. Untung S. Andriyanto dan Ir. Abdul Basith. Erlangga,Jakarta.

Mulyana, 2004. Buku Ajar Analisis Deret Waktu. Universitas Padjadjaran FMIPA Jurusan Statistika, Bandung.

Mulyono, S. 2000. Peramalan Harga Saham dan Nilai Tukar : Teknik Box-Jenkins. Ekonomi dan Keuangan Indonesia. Vol. XLVIII No. 2.

Salmon, S. H. A. 2015. Pemodelan ARIMA dalam Prediksi Penumpang Pesawat Terbang pada Bandara Internasional Sam Ratulangi Manado [skripsi]. FMIPA UNSRAT, Manado.

Sartono, B. 2006. Modul Kuliah Pelatihan Time Seties Analysis. IPB, Bogor.

Visimedia. 2016. Hukum Kasus Pidana Umum. http://www.visimediapustaka.com/hukumpraktis/464-inilah-tahapan-proses-hukumkasus-pidana-umum [24 Juli 2016]

Wei, W. W. S. 1990. Time Series Analysis:Univariate and Multivariat Methods. Addison-Wesley Publishing Company, USA.

Widarjono, A. 2005. Ekonometrika : Teori dan Aplikasi untuk Ekonomi dan Bisnis.Ekonisia, Yogyakarta 